\title{
Parameters of variation \& complement licensing in Bantu
}

\author{
Nhlanhla Thwala \\ School of Oriental and African Studies, University of London
}

In this paper I argue that the syntax of Eastern Bantu does not make reference to the notion 'syntactic object'. That is, there is no linguistic category of objects that is the target of syntactic rules in Eastern Bantu languages. Instead I propose that syntactic rules broadly distinguish complements and adjuncts ${ }^{1}$ as well as category type of complement or adjunct. I argue that Bantu languages are typologically special in that (a) the verb complement structure can be expanded by the valencyincreasing applicative suffix ${ }^{2}$; and (b) that the class of adjuncts can be expanded through verb concord licensing. Because of these properties, Bantu languages have a much-expanded notion of 'complement' and 'adjunct'. Namely, complements consist of (a) inherent complements (subcategorised by the lexical verb), and (b) derived complements (licensed by the applicative suffix). Adjuncts consist of (a) non-subcategorised modifying constituents in the usual sense and (b) phrases that are licensed by verb concord (i.e. Topics in Bresnan and Mchombo (1987)). I propose that most the differences in the licensing of objects in Bantu are due to two causes: (a) the unusual split in the composition of complements and adjuncts and (b) a set of typological parameter settings.

\section{Introduction}

Recent studies of the of the complement structure of Eastern Bantu languages are dominated by the licensing of syntactic objects, c.f. Bresnan and Mchombo (1987), De Guzman (1987), Bresnan and Moshi (1990), Rugemalira (1991), Baker (1988, 1992), Harford (1991), Woolford (1993), Ngonyani (1996) and Mchombo (2004). While object licensing has yielded many insights, large areas remain unknown about the overall complement structure of Bantu languages and how object licensing fits into the overall structure. Further, the analyses of object licensing that have emerged over the years are still unsatisfactory in many ways. The very notion of a 'syntactic object' in Bantu remains problematic

1 Subjects are not discussed in this study since they are not part of the complement structure.

2 The causative suffix introduces a subject. I do not consider it as affecting the complement structure per ser despite the occurrence of the secondary subject post-verbally. 
because we have no reliable criteria for distinguishing syntactic objects from non-object complements. The problem is that the standard object diagnostics are notorious for contradicting each other. Secondly, some of criteria do not apply in some languages leaving us with no reliable diagnostics for objects across all languages. As a result, one is led to wonder, as Schadeberg (1995) whether the criteria tell us anything about 'objecthood'. Thirdly, without relating object licensing to the general licensing of complements and adjuncts, the status of various analysis of object licensing remains unclear.

This study argues that the notion of a 'syntactic object' in Bantu is not valid. That is, there is no compelling evidence that syntactic rules make reference to or target a 'syntactic object' in Bantu. Instead, we propose that syntactic rules distinguish and target complements and adjuncts. Crucially, the notion of a complement is expanded and consists of (a) inherent complements (licensed by verb sub-categorization) and derived complements (licensed by the applicative suffix). The notion of adjunct is also expanded and consists of (a) free adjuncts with a modifying function (VP adjuncts and temporal adjuncts) and (b) derived adjuncts (viz. constituents in an anaphoric/control relationship with an incorporated pronoun or verb concord).

Based on the proposed complement-adjunct distinction, I propose two types of typological parameters: (a) macro-parameters that account for differences in the complement structure of languages cross-linguistically, as in (1), and (b) micro-parameters which follow from the choices made at the macroparameter level, as in (2).

(1) a. VC concord: Yes/No

b. Complement types: (a) inherent, or (b) inherent and derived

(2) a. VC-concord slots: One or many

b. Syntactic category that triggers VC-concord: DPs only or DPs and PPs

c. Co-occurrence of concord: Yes/No

I argue that most of the properties attributed to 'syntactic objects' in the literature fall out from the parameter settings and the complement-adjunct split.

The paper is organised as follows. Section 1 reviews the object criteria and illustrates their inadequacies. Section 2 shows that Bantu languages distinguish between complements and adjuncts generally and that the licensing of objects discussed in the literature partly follows from the licensing of the two. Section 3 discusses macro and micro typological parameters and how they can be used to account for the differences in the licensing of complements and 
adjuncts cross-linguistically and among the following Bantu languages: Kinyarwanda, Ruyambo, Chichewa, KiSwahili, Tshiluba, Setswana and SiSwati. Section 4 is the conclusion.

\section{The unreliability of the object diagnostics}

The standard diagnostics for objecthood in Bantu are summarized in (3). Although there are other diagnostics, this study will limit itself to the ones in (3) since they are the most prominent and easiest to test in many languages.

(3) a. Word order: the noun phrase which has access to the post-verbal position is an object. We refer to this criterion as the verb-adjacency test.

b. Object concord: a noun phrase that is capable of triggering object concord (OC) with the verb is an object.

c. Subjectivization in a passive construction: a noun phrase that can become the subject of a passive construction is an object.

The trouble with the diagnostics is that they are unreliable. In other words, they are neither necessary nor sufficient conditions for objecthood. Further, it is not obvious that any of the diagnostics indeed have anything to do with objecthood, as noted by Schadeberg (1995). Refer to section 2 for examples with object definition. Below we briefly illustrate the unreliability of the diagnostics. Unless indicated otherwise, the examples are from SiSwati.

\subsection{Verb adjacency}

Let us assume that it is true that the basic word order in Bantu is SVO, as in (4a). ${ }^{3}$ Placing the time adverb before the object results in ungrammaticality, as illustrated by $(4 \mathrm{~b})$. It is reasonable therefore to conclude that the position immediately after the verb is an object position (cf. Mchombo (2004)).

3 The following abbreviations are used:

$\begin{array}{llll}\text { SM } & \text { subject marker } & \text { det } & \text { determiner } \\ \text { PRG } & \text { progressive } & \text { PAST } & \text { past tense } \\ \text { PRES } & \text { present tense } & \text { Prep } & \text { preposition } \\ \text { TNS } & \text { tense } & \text { PRF } & \text { Perfect } \\ \text { OM } & \text { object marker } & \text { FUT } & \text { future tense } \\ \text { OC } & \text { object concord } & \text { FV } & \text { final vowel } \\ \text { IP } & \text { immediate past tense } & \text { PAS } & \text { passive } \\ \text { APPL } & \text { applicative } & \text { Loc } & \text { locative }\end{array}$

DSM default subject marker

The numbers preceding glosses refer to the classification number of the noun. 
(4) a. Bafana ba-tseng-e imoto itolo 1boys 1SM-buy-IP 10car yesterday 'The boys bought a car yesterday.'

b. *Bafana ba-tseng-e itolo imoto 1boys 1SM-buy-IP yesterday 10car 'The boys bought a car yesterday.'

The usual justification of the diagnostics in (3) is based on model data as in (5). The verb-adjacency criterion leads us to conclude that the underlined NPs are objects in each of the examples in (5). Further, each of the underlined NPs also meets the other two object criteria, viz. controlling object marking and raising an object to the subject position in a passive construction.

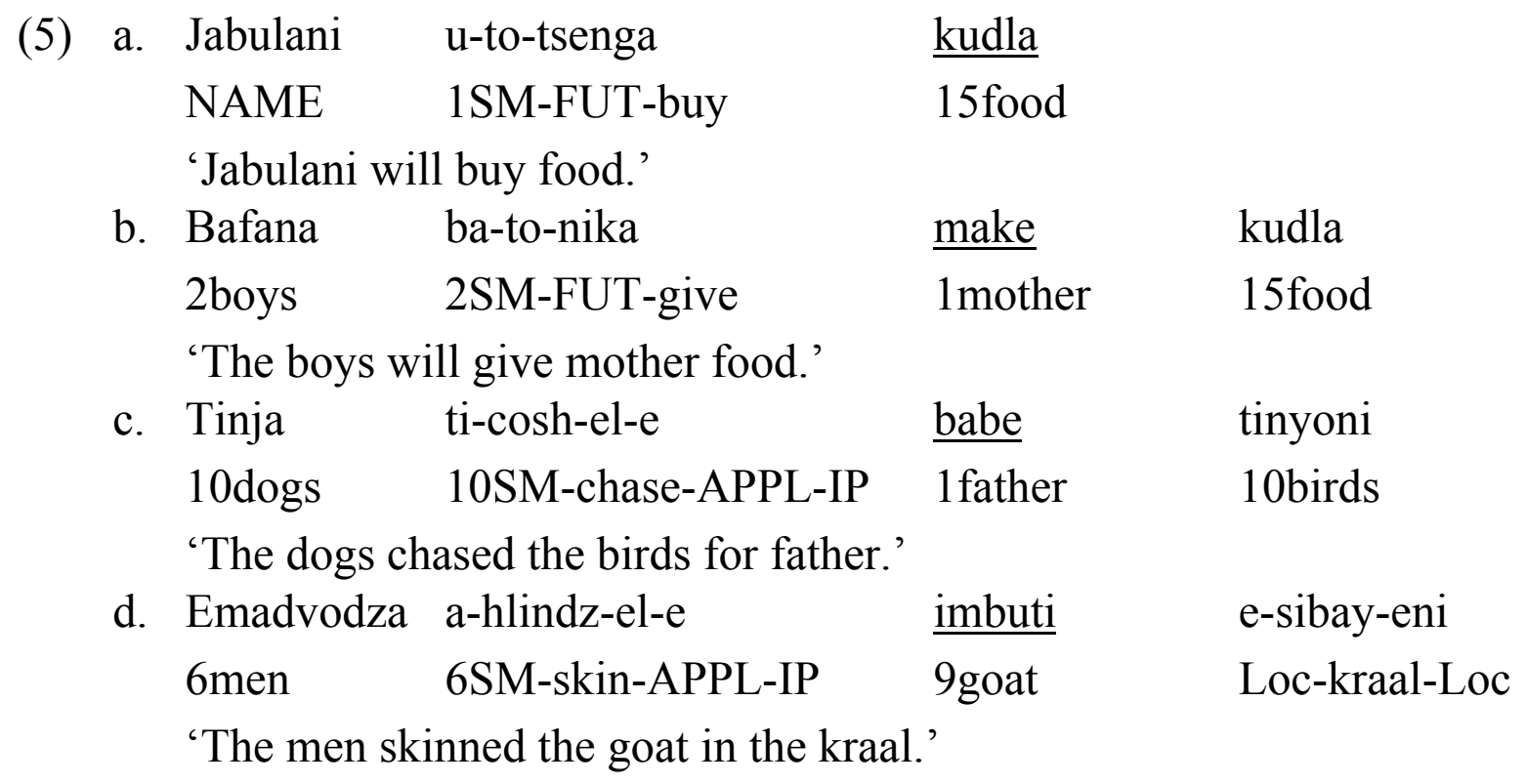

Problems with all the syntactic object diagnostics emerge when we consider data beyond the model data in (5). Take the verb-adjacency diagnostic as a starting point and the examples in (6) and (7). The prediction of the verb-adjacency test is that the underlined NPs are objects.
a. Ku-to-natsa
$\underline{\text { tsine }}$
tjwala
lamuhla
DSM-FUT-drink us
14alcohol
today
'We will drink alcohol today.'
\begin{tabular}{lll} 
b. Ku-to-fika & \multicolumn{2}{l}{ sitiemela s-anga-4 } \\
DSM-FUT-arrive & 7train 7-of-4 & now
\end{tabular}
'The 4 o'clock train will arrive now.' 

c. Ku-y-e
$\underline{\text { make }}$
e-khaya
DSM-go-IP
1 mother
Loc-home
'Mother went home.'

(7)
a. Imali
i-dlala
bantfwana
ka- Gates
4 money
4SM-play
2children
Loc-NAME
'Children play with money at Bill Gates' home.'
b. Le-moto lena i-to-hamba tsine kuphela
Det-7car this7 7SM-FUT-go us only
'Only we will travel in this car.'
$\begin{array}{lll}\text { c. Le-sikolo le-sisha } & \text { si-to-fundza } & \text { bantfabenkhosi } \\ \text { Det-7school Det-7new } & \text { 7SM-FUT-read } & \text { 2children-of-king }\end{array}$
'The king's children will study at the new school.'

However, there is strong evidence that such an analysis is not correct. Each of the NPs which verb-adjacency test predicts are objects in (6-7) also occur as grammatical subjects, as illustrated in (8-9). Further, the meaning of these constructions suggests that the underlined NPs in (6-7) are always subjects as in (8-9). ${ }^{4}$ Consequently, there is no meaning difference between (6-7) and (8-9).
(8) a. Tsine
si-to-natsa
tjwala
lamuhla
$\mathrm{We}\left(2^{\text {nd }} \mathrm{pl}\right)$
$\mathrm{SM}\left(2^{\text {nd }} \mathrm{pl}\right)$
'We will drink alcohol today.'
Sitimela s-anga-4 si-to-fika
14alcohol today
b. Sitimela s-anga-4 si-to-fika manje
7train 7-of-4 7SM-FUT-arrive now
'The 4 o'clock train will arrive now.'
c. Make
u-y-e
e-khaya
1 mother
1SM-go-IP
Loc-home
'Mother went home.'

(9)
a. Bantfwana
ba-dlala
nge-mali
ka-Gates
2children
2SM-play
with-8money
at-Gates
'Children play with money at Gate's home.'
b. Tsine
si-to-hamba
nga-le-moto lena
we
SM-FUT-go
with-det-7car 7this
'We will go in this car.'

\footnotetext{
4 But see Marten (this volume) and Morimoto (this volume) for pragmatic differences of these constructions in other Bantu languages.
} 


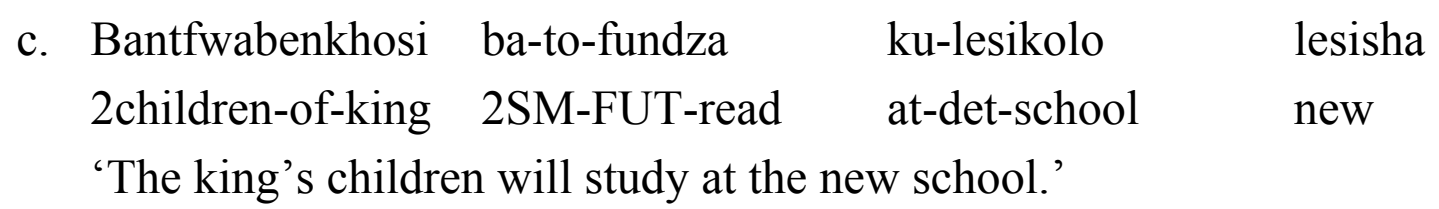

The problem is as follows. Since the verb-adjacency test is not sensitive to verb classes (unergatives/accusatives) or subject inversion, it cannot tell apart noun phrases which are internal arguments/objects from noun phrases which are external arguments/subjects. It wrongly categorizes external arguments as objects in the presentation focus constructions in (6) and in the subject-object reversal constructions in (7).

\subsection{Verb adjacency and $O M$ control}

The diagnostics are also unreliable because they sometimes contradict each other. Consider, for example, (10-11) in light of the verb-adjacency test. We have to say that the underlined constituents are objects in (6-7) because they immediately follow the verb. But (10-11) suggests that the underlined constituents are not objects because they fail to control object concord. The verb-adjacency test and the OM control test lead to contradicting conclusions. ${ }^{5}$
a. *Ku-to-si-natsa
tjwala
$\underline{\text { tsine }}$
DSM-FUT- ${ }^{\text {st }}$ pl.OM-drink
14alcohol
we $\left(1^{\text {st }} \mathrm{pl}\right)$
b. *Ku-to-si-fika
manje
sitimela s-anga-4
DSM-FUT-7OM-arrive now
c. $\quad *$ Ku-m-y-e
e-khaya
7train 7-of-4 o'clock
DSM-1OM-go-IP
Loc-home
$\underline{\text { make }}$
1 mother

(11)
a. * Imali
i-ya-ba-dlala
4 money
4SM-PRG-2OM-play
ka-Bill Gates
bantfwana
b. * Le-moto lena
i-to-si-hamba
Loc-Name
2children
Det-8car this
8SM-FUT- ${ }^{\text {st }}$ pl.OM-go
kuphela, tsine
c.
Det- 7 school
si-to-ba-fundza
only
us $\left(1^{\text {st }} \mathrm{pl}\right)$
bantfwabenkhosi.
7SM-FUT-2OM-read
children_of_king

5 An anonymous reviewer suggests that $\mathrm{OM}$ control may be the only reliable test for objecthood. But the problem arises in Kinyarwanda (see 14a) where PPs which do not qualify as objects also control OM. 


\subsection{Animacy hierarchy}

Evidence from Runyambo (cf. Rugemalira (1991)) also suggests that the verb adjacency test in not useful as an object diagnostic. This is because the DP complement that occurs adjacent to the verb is the highest in the animacy hierarchy. So, if we believe the verb-adjacency test, only Kato is the object in (12). But as (12) below shows, both Kato and ebitooce are capable of object control, suggesting that both are objects according to the OC control test.

$$
\begin{array}{llll}
\text { a. } & \text { a-ka-teec-er-a } & \text { kató } & \text { ebitooce } \\
\text { she-PAST-cook-APPL-FV } & \text { Kato } & \text { bananas } \\
\text { b. } & * a-k a-t e e c-e r-a & \text { ebitooce } & \text { kató } \\
& \text { she-PAST-cook-APPL-FV } & \text { bananas } & \text { Kato } \\
& & \multicolumn{2}{r}{\text { Runyambo cited from Rugemalira (1991) }}
\end{array}
$$

It is possible to say that both DP complements qualify as objects in (12) and that verb adjacency (as an object test) applies but that it is voided by a stronger semantic (animacy) constraint. The problem with such a stance is inconsistency and possibly an un falsifiable set of claims. If the diagnostics can be voided, the principles that govern voiding should be spelled out. Otherwise it will never be possible to falsify the diagnostics. I am not aware of such principle, however. Further, while the animacy hierarchy effects are widespread in Bantu languages, they do not apply in all languages and they do not have similar effects in all languages even when they do apply. Therefore, it is not predictable (a) what effects they have and (b) where they have them. For example, in Swahili, the animacy effects determine the DP complement that controls OC and have nothing to do with word order. But in Runyambo they determine the DP complement that must be adjacent to the verb and have nothing to do with OC control.

\subsection{Contradiction between OM and subjectivization}

The problem is not limited to the verb-adjacency test. There are problems with the other diagnostics as well. Rugemalira (1991) notes that the OC control test and the subjectivization of an object (in passive constructions) test also contradict each other. Thus in Runyambo only one object in double object constructions can occur as the subject of a passive construction (13a-b). Yet both objects can trigger object concord (13c). So, the subjectivization test in passive constructions says there is one object. But the object concord control test says there are two objects. 
(13) Runyambo ( Rugemalira (1991))

a. omwááná (ebiráátwa) a-ka-bi-reet-er-w-á child (shoes) he-PAST-them-her-bring-APPL-FV omuséíjá man

'The child was bought them (shoes) by a man.'

b. *ebiráátwá (omwáána) bi-ka-mu-reet-er-w-á omuséíjá shoes (child) they-PAST-her-bring-APPL- man PAS-FV

'shoes were bought for her (child) by a man'

c. omuséíjá a-ka-bi-mu-réé-er-a man he-PAST-them-her-bring-APPL-FV

'The man bought them for her.'

\subsection{OM control is extended beyond prototypical objects}

Whereas it is admittedly difficult to define objects in structural terms, there is nonetheless wide consensus that objects are nominals that occur as verb complements (i.e. internal arguments). Thus PPs (whether they are locatives or instruments) are not usually considered to be objects. The problem with using OC control as an object diagnostic is that it is not controlled by noun phrases alone. In Kinyarwanda and Chichewa and Swahili, OC can be controlled by locative prepositional phrases, as illustrated below.

(14) a. Kuu ntebe, abaana ba-ra-h-iica-ye on chair children they-PRES-there-sit-ASP

'On the chair the children are sitting on it.'

Kinyarwanda cited in Gerdts et al. (1998)

b. Alenje a-ku-pa-lik-ir-a mikeka (pa-mchenga) hunters SM-PRES-OM-weave-appl- mats ind

'The hunters are weaving mats in it.'

c. Ni-na-pa-ju-a

SM1sg-PRES-OM16-know-FV

'I know it (there).' 
Given (14) we cannot rely on OC to be diagnostic of objects in the usual sense of the word. The notion of OC control extends beyond objects since the category of PPs also control OC. Given that state of affairs, OM control cannot be used as a diagnostic for objecthood. If we allow preposition phrases, as in (14), to be objects, the notion of an object becomes imprecise. Further, what follows from the analysis is bizarre. Namely, whereas we have to say that PPs are objects in Kinyarwanda, Chichewa and Swahili, we also have to say PPs are not objects in languages like SiSwati where they fail to control OC and other object tests. Such a conclusion is not warranted. We do not expect objecthood to be variable, restricted to DPs in some languages and extending to PPs in other languages. Not least in related languages such as the case here.

\subsection{Symmetric and non-symmetric objects}

In Bresnan and Moshi (1990) it is proposed that in double object constructions objects can be described as either symmetric or asymmetric. The main idea is that objects are symmetric if they are treated in similar ways by the object diagnostics in (3).

We have already shown that the diagnostics for objecthood are unreliable at best. In this section we show that the three criteria do not pattern together so as to predict the symmetric/asymmetric split. And as a result I argue that the diagnostics cannot be the basis of parametric variation among languages. This inevitably raises doubts about the validity of the symmetric/asymmetric object split in Bantu.

The proposal that there are symmetric and asymmetric objects depends on the existence of diagnostics for the parameter. But as Rugemelira (1991) has observed, there is strong evidence that there are no symmetric/asymmetric languages. Rather, there are various strategies (some semantic, and some morphological and some syntactic) that languages use to distinguish internal arguments. He cites the following evidence to challenge the symmetric/asymmetric language split:

Verb adjacency contradicts OC control: In Runyambo, the NP that follows the verb in double object constructions is the highest in the animacy hierarchy (15a). Based on that pattern, we might conclude that Runyambo is an asymmetric language. But the $\mathrm{OC}$ control evidence contradicts this conclusion. Both nominal complements can control object concord, as illustrated in (15c), suggesting that Runyambo is symmetric. 
(15)
a. a-ka-teec-er-a kató ebitooce
she-PAST- cook-APPL-FV Kato bananas
b. *a-ka-teec-er-a ebitooce kató she-PAST-cook-APPL-FV bananas Kato
c. omuséíjá a-ka-bi-mu-réét-er-a
man he-PAST-them-her-bring-APPL-FV
'The man bought them for her.'

Runyambo, cited from Rugemalira (1991)

In Swahili, object concord is obligatory with the noun phrase complement that is highest in the animacy hierarchy. Word order is free and so both DP complements have access to the post verbal position. This suggests that Swahili is a symmetric language. But considering the $\mathrm{OC}$ concord evidence suggests the opposite since only the NP that is highest in the animacy hierarchy can trigger object concord. Again we have a contradiction and Swahili exhibits both symmetric and asymmetric object properties.

\begin{tabular}{rlrl} 
(16) a. & *a-li-pik-i-a & \multicolumn{1}{c}{ kato } & ndizi \\
& she-PAST-cook-APPL-FV & Kato & bananas \\
& 'She cooked bananas for Kato.' & \\
b. & $\begin{array}{l}\text { a-li-pik-i- a } \\
\text { ndizi }\end{array}$ & kato \\
& she-PAST-cook-APPL-FV & banana & Kato \\
c. & a-li-m-pik-i-a & kato & ndizi \\
& she-PAST-him-cook-APPL-FV & Kato & bananas \\
& 'She cooked bananas for Kato.' & & \\
d. & $\begin{array}{l}\text { a-li-m-pik-i-a } \\
\text { she-PAST-him-cook-APPL-FV }\end{array}$ & bananas & Kato \\
& 'she cooked bananas for Kato.' & &
\end{tabular}

Swahili, cited from Rugemalira (1991)

Subjectivization in passives contradicts OC control: As noted above, there is also a contradiction regarding subjectivization and OC control in Runyambo. Namely, only one object in double object constructions can occur as the subject of a passive construction. This suggests that the objects are asymmetrical. Yet both objects can trigger object concord otherwise, suggesting that objects are symmetrical.

The problems do not just occur in Runyambo and Swahili. In SiSwati, objects exhibit both symmetric and asymmetric properties (cf. De Guzman (1987)). SiSwati allows one object concord at a time. It exhibits both symmetric 
and asymmetric object properties depending on the tense/mood of the sentence. The present progressive tense (marked by the affix $y a$-), and the perfect tense (marked by -ile), exhibit symmetric properties in terms of word order. But they exhibit asymmetric properties in object marking. So, both objects have access to the post-verbal position, as illustrated in (17).

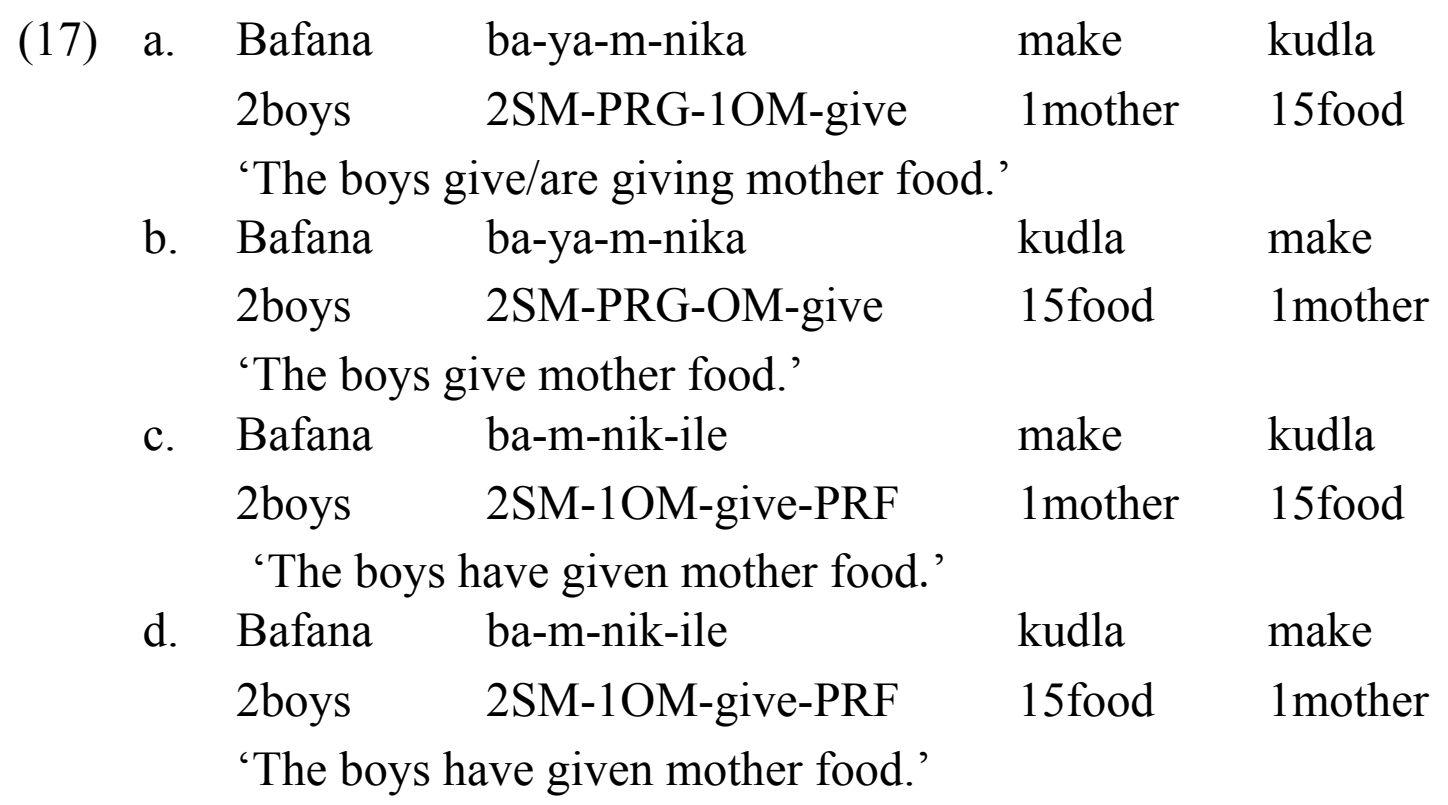

But the objects exhibit asymmetric properties with regards to $\mathrm{OC}$ control because all the sentences in (18) are very odd to ungrammatical when the OC is controlled by the noun phrase bearing the thematic role of patient.

$\begin{array}{rllll}\text { (18) a. } & \text { ??Bafana } & \text { ba-ya-ku-nika } & \text { make } & \text { kudla } \\ & \text { 2boys } & \text { 2SM-PRG-15OM-give } & 1 \text { mother } & 15 \text { food } \\ \text { b. } & \text { ?? Bafana } & \text { ba-ya-ku-nika } & \text { kudla } & \text { make } \\ & \text { 2boys } & \text { 2SM-PRG-15OM-give } & 1 \text { mother } & 1 \text { mother } \\ \text { c. } & * \text { Bafana } & \text { ba-ku-nik-ile } & \text { make } & \text { kudla } \\ & \text { 2boys } & \text { 2SM-15OM-give-PRF } & 1 \text { mother } & 15 \text { food } \\ \text { d. } & \text { *Bafana } & \text { ba-ku-nik-ile } & \text { kudla } & \text { make } \\ & \text { 2boys } & \text { 2SM-15OM-give-PRF } & 15 \text { food } & 1 \text { mother }\end{array}$

In contrast, sentences that are in the immediate past tense, remote past tense and future tense exhibit symmetric properties with OC control; but exhibit asymmetric properties in word order. Thus, if OC does not occur in (19) there is 
strict word order of: $\mathrm{V}>\mathrm{DP}_{\mathrm{RECIPIENT}}>\mathrm{DP}_{\mathrm{PATIENT}}$ for declarative neutral reading. ${ }^{6}$ Thus (19b) is ungrammatical under these conditions.

$\begin{array}{llll}\text { a. Bantfwana ba-to-nika } \quad \text { make } & \text { kudla } \\ & \text { 2children } & \text { 2SM-FUT-give 1mother } & \text { 15food } \\ \text { 'The children will give mother food.' } & \\ \text { b. } & \text { *Bafana } \quad \text { ba-to-nika } \quad \text { kudla } & \text { make } \\ & \begin{array}{l}\text { 2boys } \\ \text { 'The boys will give food to mother.' }\end{array}\end{array}$

But both nominal complements can trigger OC, as illustrated in (20). Further, the noun that controls $\mathrm{OC}$ cannot be adjacent to the verb in a neutral reading.

$\begin{array}{lllll}\text { a. Bafana ba-to-m-nika } & \text { kudla } & \text { make } \\ \text { 2boys } & \text { 2SM-FUT-1OM-give } & 15 \text { food } & \text { 1mother } \\ \text { 'The boys will give mother food.' } & & \\ \text { b. Bafana ba-to-ku-nika } & \text { make } & \text { kudla } \\ & \begin{array}{l}\text { 2boys } \quad \text { 2SM-FUT-15OM-give } \\ \text { 'The boys will give food to mother.' }\end{array} & & 1 \text { mother } & \text { 15food }\end{array}$

SiSwati is therefore a language that exhibits both symmetric and asymmetric properties.

Having observed other problems with the diagnostics for symmetric and asymmetric objects in Kitharaka, Harford (1991) concludes that symmetric languages can be distinguished in terms of the co-occurrence of object properties. For example, as when a passive verb triggers OC with one object and triggers SC with the subjectivized object. The modification does not rescue the diagnostics in SiSwati. This is because when the subjectivized object is the noun phrase bearing the role of patient, OM control by the recipient NP is ungrammatical, as (21b) shows (cf. De Guzman (1987)). But if the subjectivized NP is the recipient, object control by the patient NP is grammatical. To account for (21b) we have to conclude that SiSwati objects are asymmetrical. But given (21d) we have to say they are symmetrical. Again, we have a contradiction.

6 The strict word order obtains only in a neutral declarative reading. Otherwise, word order in (19b) is possible if the recipient DP is contrastively focused. 
(21)
a. Kudla ku-nik-w-e
make
nge-banfana
15 food 15SM-give-PAS-IP
1 mother
by-2boys
'Food was given (to) mother by boys.'
b. *Kudla ku-m-nik-w-e nge-bafana make
15 food 15SM-1OM-give-PAS-IP by-2boys 1mother
'Food was given to mother by boys.'
c. Make u-ku-nik-w-e nge-bantfwana kudla
1mother 1SM-15OM-give-PAS-IP by-2children 15 food
'Mother was given the food by children.'
d. Make u-lu-nik-w-e nge-bantfwana lutsi
1mother 1SM-11OM-give-PAS-IP by-2children 11stick
'Mother was given the stick by children.'

Alsina's (1996) theory of objects does not solve the problems raised by SiSwati. Space limitations prevent me from commenting in detail. The following brief observations are in order. Firstly, Alsina does not use verb-adjacency as diagnostic of objecthood. We can only assume that it should no longer be used as an object diagnostic. Secondly, Alsina's analysis will still have to analyse the objects in the -ile and $y a$ - forms as asymmetric while analysing all other objects as symmetric in SiSwati. ${ }^{7}$ I take this to mean that the (a)symmetry of objects is not a parameter as such, but a construction-specific rule. Thirdly it is an open question whether a universal thematic prominence hierarchy is empirically justified and that it should rule out (21b) or whether we should seek an alternative analysis for behaviour of complements in general.

In summary, the preceding discussion has cast doubt that there are empirically valid syntactic diagnostics for objecthood that can be used across Eastern Bantu languages. It has also cast doubt that there is a valid parameter of (a)symmetric objects. Crucially, the object criteria do not pattern in a predictable fashion. So OC does not co-occur with all passive constructions; and verb adjacency does not mean the object has access to object control or the subject of the passive construction. We have also argued that the improved diagnostic for symmetric languages proposed by Harford (1991) and the theory of objects proposed by in Alsina (1996) do not solve the problem in SiSwati. This is because the language exhibits both symmetric and asymmetric effects that are not predictable from the theory objects. I take this to show that the symmetric/asymmetric split is not a valid parameter.

7 Alternatively, another analysis is required to explain why objects in the -ile/ya- paradigms are not symmetric. But that path would only serve to proliferate the ancillary accounts required to prop us the theory of objects. 


\subsection{The complement structure of Bantu}

In this section I propose that complements in Bantu must be broken down into two main categories (a) inherent complements and (b) derived complements. The notion of an inherent complement is a subset of the notion of subcategorization. So, whereas inherent argument refers to all arguments that are sub-categorized by a verb, inherent complement refers to internal arguments of a verb (cf. Williams (1980)). For the purposes of this study I will assume that subcategorization distinguishes between external and internal arguments. A derived argument refers to constituents that are licensed by the applicative suffix. Crucially, those constituents behave like complements and thus constitute the extended argument structure of the verb.

I also propose that adjuncts break down into two categories of (a) free adjuncts and (b) derived adjuncts. A 'free adjunct' refers to sentential and VP modifying constituents like adverbs and prepositional phrases whose inclusion in the construction is syntactically optional. Crucially, free adjuncts are not licensed by sub-categorization or the applicative suffix. A 'derived adjunct' refers to constituents that trigger concord with the verb or are Topics in an anaphoric relationship with incorporated pronouns in the vocabulary of Bresnan and Mchombo (1987). Crucially, Topics are optional in the construction.

\subsection{Inherent complements and derived complements}

Bantu languages are typologically distinguished by the fact that the complement structure is more elaborate than in a language like English. Whereas lexical verbs in Bantu and English are similar in that they sub-categorize for complements, the lexical verb in Bantu differs in that its complement structure can be extended by the applicative suffix. The argument that is licensed by the applicative suffix will be referred to as the derived complement. We therefore conclude that there are two types of complements in Bantu: inherent and derived complements. This study will have nothing to say about external arguments or the causee argument in causative constructions.

The complement structure of the verb in Bantu is summarised as in (22). Inherent complements generally consist of DPs, PPs and clauses. Derived complements also include DPs, PPs and clauses as I show below.

Complement structure Inherent complements

$\begin{array}{lll}\text { Intransitive } & \mathrm{V}>\varnothing & \mathrm{V}-\mathrm{APPL}>\mathrm{YP} \\ \text { Mono-transitive } & \mathrm{V}>\mathrm{XP} & \mathrm{V}-\mathrm{APPL}>\mathrm{YP}_{\mathrm{APPL}}>\mathrm{XP} \\ \text { Di-transitive } & \mathrm{V}>\mathrm{XP}>\mathrm{ZP} & \mathrm{V}-\mathrm{APPL}>\mathrm{YP}>\mathrm{XP}>\mathrm{ZP}\end{array}$


The licensing relationship between the applicative and the derived complement is illustrated in (23). In (23a) the locative phrase is optional, and therefore an adjunct. But in (23b) it is obligatory. Nouns can also be licensed by the applicative, as the contrast between (23c-d) shows. Thus in (23c) the lexical verb cannot license two noun phrase complements on its own, hence the ungrammaticality. But in (23d) both noun phrase complements are licensed. The noun phrase bearing the role of benefactive is licensed by the applicative, while the noun phrase bearing the role of patient is licensed by the lexical verb.

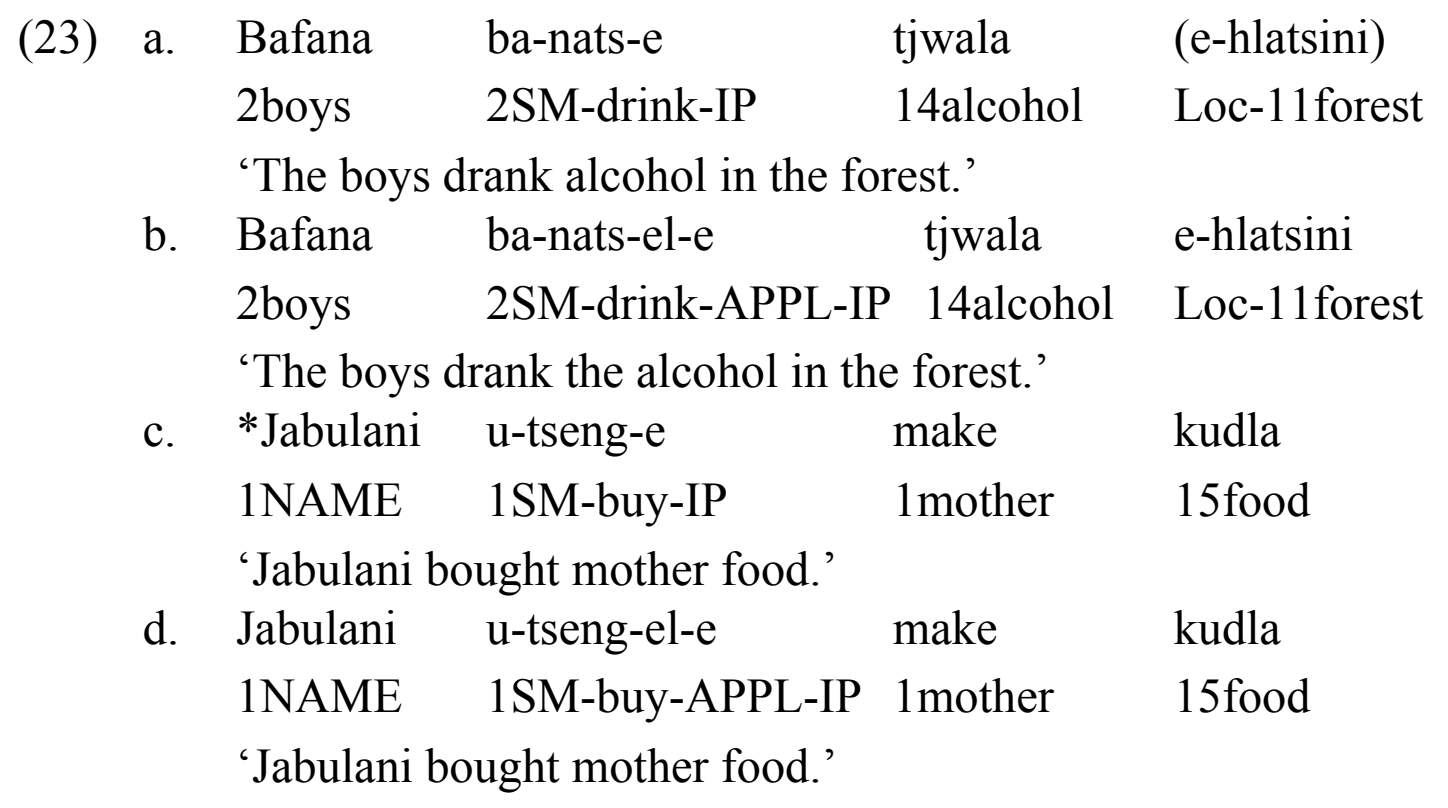

\subsection{Licensing properties of lexical verbs and the applicative}

There are differences in the licensing properties of lexical verbs and the applicative suffix. Whereas every lexical verb sub-categorizes its arguments for a given event description, the applicative only licenses arguments which are compatible with the properties the lexical verb. Thus, the verb -fika 'arrive', (which sub-categorizes one argument in (24a)), can combine with the applicative and license a locative prepositional phrase complement in (24b). However, a non-locative preposition phrase cannot be licensed by the applicative suffix, as illustrated by the ungrammaticality of (24c). Further, a noun phrase cannot be licensed by the applicative in this context (24d).

$$
\begin{aligned}
& \text { a. Bafana ba-to-fika } \\
& \text { 2boys 2SM-FUT-arrive } \\
& \text { 'The boys will arrive.' }
\end{aligned}
$$



b. Bafana ba-to-fik-el-a ka-mi/ e-sitolo 2boys 2SM-FUT-arrive-APPL-FV Loc- ${ }^{\text {st }}$.sg Loc-store
'The boys will arrive at my place/at the store.'
c. *Bafana ba-to-fik-el-a na-mi
2boys 2SM-FUT-arrive-APPL-FV with-me
'The boys will arrive at/with me.'

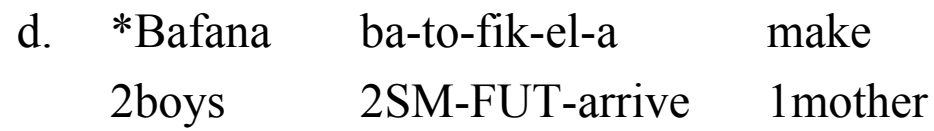
'The boys will arrive at/for mother.'

The situation is different with a transitive verb like -tsenga 'buy/shop.' In that case, the applicative can license a noun phrase but not a locative prepositional phrase. Thus, under the 'buy' reading, the applicative licenses a benefactive DP complement in $(25 \mathrm{~b})$ but fails to license the locative prepositional phrase in $(25 \mathrm{c})$. Also, under the 'shop' reading in (25d) the applicative licenses the benefactive noun phrase complement but not the locative phrase that remains optional (and thus is considered to be an adjunct).
u-to-tsenga
kudla
1NAME
1SM-FUT-buy
15 food
'Jabulani will buy food.'

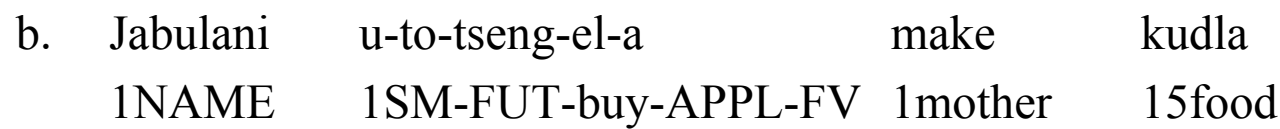
'Jabulani will buy food for mother.'
c. Jabulani u-to-tseng-el-a kudla e-sitolo
1NAME 1SM-FUT-buy-APPL-FV 15 food Loc-store
'Jabulani will buy food while at the store.'
$\begin{array}{llll}\text { d. Jabulani } & \text { u-to-tseng-el-a } & \text { make } & \text { e-sitolo } \\ \text { 1NAME } & \text { 1SM-FUT-buy-APPL-FV } & \text { 1mother } & \text { Loc-store }\end{array}$
'Jabulani will shop for mother at the store.'

The generalization is the following. The arguments that are licensed by the lexical verb are determined by its lexical semantics. The applicative suffix only licenses arguments that are compatible with the lexical semantics of the lexical verb. This is because the applicative has no independent event structure. Instead, it depends on the lexical verb to provide the event structure for its argument. Naturally, whatever argument is introduced by the applicative must be 
compatible with the properties of events denoted by the verb and its inherent arguments.

\subsection{Syntax can see both derived and inherent complements}

One of the predictions of the analysis is the following. If the complement structure can be expanded we expect the derived complements to be subject to rules that apply to inherent complements. That is, all rules that apply to inherent complements should also apply to derived complements. This is the case as the evidence below shows.

First, if both the lexical verb and the applicative license DP complements, the neutral declarative word order is $\mathrm{V}>\mathrm{NP}_{\mathrm{APP}}>\mathrm{NP}_{\mathrm{LEX}}$, as in (26). The following conclusion can be reached. The applicative DP argument precedes the lexical verb DP complement.

$\begin{array}{llll}\text { Make u-fundz-el-e } & \text { bantfwana } & \text { libhayibheli } \\ \text { 1mother } & \text { 1SM-read-APPL-IP } & \text { 2children } & \text { 5bible } \\ \text { 'Mother read the bible for the children.' } & \end{array}$

Confirmation of this generalization is seen in double object constructions. The verb -beka 'take' sub-categorizes a DP and a PP complement. The applicative combines with the verb to licenses another DP complement. The applicative DP must, however, precede the lexical verb DP complement, as in (27a), giving rise to the word order: $\mathrm{V}>\mathrm{NP}_{\mathrm{APPL} / \mathrm{BEN}}>\mathrm{NP}_{\mathrm{LEX} / \mathrm{PAT}}>\mathrm{PP}_{\mathrm{LEX} / \mathrm{LOC}}$. Reversing the order of DPs, as in (27b) is ungrammatical.
a. Emaphoyisa a-bek-el-e
make kudla
nga-phandle
6police
6SM-put-APPL-IP 1mother 15food
loc-outside
'The police put food for mother outside.'
b. *Emaphoyisa a-bek-el-e kudla make ngaphandle 6police 6SM-put-APPL-IP 15food 1mother outside
'The police put food for mother outside.'

Second, an NP complement of the lexical verb precedes a PP complement of the applicative as in (28b) in a neutral declarative reading. This is a critical observation since it means that not all arguments of the applicative precede the lexical verb arguments in a neutral reading. We therefore cannot appeal to a generic rule that says applied complements always precede lexical verb complements. Rather, syntax is also sensitive to the category type of the complement. Thus, DPs precede non-DP complements regardless of the head 
that licenses them. So the order $* \mathrm{~V}>\mathrm{PP}>\mathrm{DP}$ is never realized where DP does not trigger concord with the verb in a neutral declarative reading.
a. Bafana ba-to-dlala ibhola 2boys 2SM-FUT-play ball
'Boys will play ball.'
b. Bafana ba-to-dlal-el-a ibhola ngaphandle 2boys 2SM-FUT-play-APPL-FV ball outside
'Boys will play ball outside.'

Third, an interesting word order constraint is observed when the applicative licenses a purpose/goal complement and the lexical verb subcategorizes a DP complement in SiSwati. ${ }^{8}$ The two complements cannot co-occur as lexical phrases when neither of them triggers $\mathrm{OC}$, as illustrated by the ungrammaticality of (29a). The only strategy available for licensing the DP complement is OC, as in (29b). The lexical DP can thus be expressed as a Topic dislocated to the left or to the right.
a. *Bafana ba-dlal-el-a
ibhola imali
2boys 2SM-play-APPL-FV 4ball 4money
'Boys play ball for money.'
b. (Ibhola) bafana ba-yi-dlal-el-a imali (ibhola) 4ball 2boys 2SM-4OM-play-APPL-FV 4money 4ball
'The ball, boys play it for money.'
'Boys play it for money, the ball.'

In summary, this section has shown that derived complements are subject to the word order constraints that apply to inherent complements. For example, applicative complements generally preceded lexical verb complements. Hence, if the verb and the applicative both license DP complements or if both license $\mathrm{PP}_{\mathrm{LOC}}$ complements, the applicative complement will be ordered before the lexical verb complement. However, there are some exceptions to this word order. Syntax is also sensitive to category type. Hence, DPs precede PP

\footnotetext{
8 Kinyarwanda does not have this constraints since the goal argument can occur overtly as in the following example from Kimenyi's webpage (Kinyarwanda Applicatives Revisited: www.kimenyi.com/kinyarwanda-applicatives-revisited.php):
}

(i) Umugabo a-ra-som-er-a igitabo amatsiko.

'The man is reading the book for curiosity.' 
complements, regardless of the licensing head. We also noted that a DP purpose/goal applicative complement and a lexical verb DP complement cannot co-occur when neither trigger OC. Instead, the lexical verb DP complement is forced to trigger OC, allowing only the applicative DP complement to be licensed structurally in the post-verbal position.

\subsection{Adjuncts versus complements}

The most direct way of distinguishing syntactic adjuncts from complements is by optionality in the sentence (cf. Marten (2002) for a different view of adjunct licensing). Adjuncts may be left out of the sentence without causing ungrammaticality, as the constituents in brackets in (30c-d) show. In contrast, complements cannot be left out as the ungrammaticality of (30a-b) shows.
a. *Bafana ba-to-nika
2boys
2SM-FUT-give
'Boys will give.'
b. *Babe u-to-hamb-el-a
1 father 1SM-FUT-go-APPL-FV
'Father will leave for.'
c. Emaphoyisa a-y-e e-khaya (itolo/namuhla) 6police 6SM-go-IP Loc-home yesterday/today
'The police went home yesterday.'
d. Bantfwana ba-to-dlala (kahle/nge-moto/na-mi) (kusasa) 2children 2SM-FUT-play well/with-car/with-me tomorrow 'Children will play well/with a car/with me tomorrow.'

Adjuncts broadly break down into two types in Bantu: free adjuncts and derived adjuncts. Free adjuncts broadly refer to all modifying constituents such as temporal adverbs or manner adverbs, or locative phrases, or prepositional phrases, whose occurrence in a sentence is not part of the sub-categorization of the lexical verb or the applicative suffix licensing. Derived adjuncts on the other hand refer to constituents whose adjunct status is licensed directly by the syntax/morphology through an agreement affix or pronominal element. That is, such constituents become optional because there is a pro-form constituent within the sentence that fulfils their syntactic function. In short, only constituents that are in an agreement/anaphoric relationship with the verb or clause can be derived adjuncts. Thus in (31) all the underlined phrases are derived adjuncts. 
(31)
a. (Bafana $\left.{ }_{\mathrm{j}}\right)$ emaphoyisa a-ya-ba-funa
2boys police SM-TNS-2OM-want
'As for boys, the police want them.'
b. (E-khaya $\left.{ }_{j}\right)$ ngi-ya khona
Loc-home $\quad 1^{\text {st }}$ sg-go there
'As for home, I am going there.'
c. (Nga-phandle $\mathrm{N}_{\mathrm{j}}$, make u-bek-e kudla khona Prep-outside 1mother 1SM-put-PAST food there 'As for outside, mother put food there.'

Bantu languages differ in the strategies they deploy to license DPs and locatives as derived adjuncts. Here we focus only on the OC strategy and resumptive strategy. There are languages like SiSwati in which DPs are the only constituents that can be licensed via OC. Since locatives are PPs in those languages, they cannot be licensed via OC. The only available strategy for licensing them as derived adjuncts is the resumptive strategy, as in (31b-c). On the other hand there are languages like Chichewa and Kinyarwanda which license both locatives and DPs via OC (see (14) locative licensing through OC). In other words, the class of locative is treated exactly the same way as DPs in these languages because both can control OC. It is important to note that the class of derived adjuncts we are proposing will be the same regardless of the strategy of licensing. So, in both SiSwati and Chichewa/Kinyarwanda locatives will be derived adjuncts, albeit via different routes. In order to capture the fact that OC control is not strictly a property of DP complements but also includes PP complements in some languages (see Kinyarwanda, Chichewa, and Swahili in (14a)), we will henceforth refer to all so-called object concord as verbcomplement concord, abbreviated as VC-concord.

To summarize, the complement structure of Bantu consists of inherent complements and derived complements. There is evidence that syntax treats derived complements to the same word order constraints as inherent complements. The class of adjuncts is also divided into two. On one hand there are free adjuncts and on the other there are derived adjuncts. The crucial difference between them is that free adjuncts are not licensed by subcategorization or the applicative suffix. Such adjuncts serve as modifies of the event denoted by the proposition in terms of event time, manner of the event, or the location of the event. Derived adjuncts differ in that an anaphoric/agreement constituent within the sentence licenses them. Finally, Bantu languages differ lexically in the type of strategies they deploy to license derived locative adjuncts. Whereas some languages use the VC-concord strategy other languages 
use the resumptive strategy. All Bantu languages use the VC-concord strategy to license derived DP adjuncts.

\section{$4 \quad$ Parameters of variation}

In this section I show that some of the major differences among Bantu languages follow from two kinds of typological parametric choices: macro parameters that distinguish languages generally and micro parameters that distinguish languages that have opted for the same macro parameters. In general, macro parameters cut across language phyla. Micro parameters on the other hand characterise languages that share macro parameters and frequently these are related languages although not exclusively. I propose that the complement and adjunct structure of Bantu languages we have discussed has its genesis in the choices made at the macro parameter level in (32).
a. VC-concord: Yes/No
b. Complements: inherent only or inherent and derived

The choice of either macro parameter has consequences. If a language chooses the negative value of (32a), then it will be like English and other languages that do not allow VC-concord. But if a language chooses the positive value of (32a), the micro-parameters in (33) must be addressed. If a language chooses inherent complements only in (32b), it is limited to licensing complements through subcategorization. But if a language chooses both inherent and derived complements, has to contend with the strategy of licensing inherent and derived complements. Clearly the strategies of licensing are not the same. Bantu languages are presented the choices in (33), but languages like English use other strategies which enable a sentence like, 'John had Bill sweep the floor clean' which express both a causative and resultative semantics.
(33) a. VC-concord slots: One or many?
b. VC-concord categories: DPs only or DPs and PPs?
c. Co-occurrence of concord: Yes/No?

\subsection{Micro-parameters of variation}

It is clear that Bantu languages are similar at the macro parameter level since they all exhibit $\mathrm{VC}$-concord and they all license inherent and derived complements. Differences are found at the micro parameter level, as in (33). 
Below we outline the consequences of each micro parameter and how the different languages pattern according to the choices they make.

\subsubsection{VC-concord slots: one or many?}

This is a binary parameter in which languages make a choice of one or many VC-concord slots at a time. We therefore propose that there are no languages that select two or three slots, confirming the often-cited notion that languages do not count. In principle, any number of VC-concord slots is possible. Constraints to the attested VC-concord slots are a function of other parametric choices, such as whether other categories other than DPs can control OC. Also, the valency of the verb is another constraint. We may also want to processing and memory constraints as additional constraints to an infinite number of VC-slots attested.

Differences between KiSwahili, SiSwati and Chichewa on one hand and Kinyarwanda, Runyambo, and Tswana on the other hand can be accounted by the choices they make at this micro parameter. The former select one $\mathrm{VC}$ concord slot whereas the latter select many VC-concord slots. Available data suggests that Kinyarwanda is the only language that fully exploits the most slots. In (34) four VC-slots are used. Other languages tend to exploit a maximum of two VC-slots. For example, in Tswana, only two VC-slots seem to be attested. ${ }^{9}$

Abaana ba-zaa-ha-ki-mu-b-eerek-er-a

Children they-FUT-there-it-him-them-show-APPL-ASP

'The children will show it to him for them there.'

Kinyarwanda data cited in Alsina (1996)

It remains a project for future research to determine fully the constraints that limit the VC-slots languages exploit.

\subsubsection{VC-concord with DPs only or with DPs and PPs}

This parameter groups languages like Chichewa and Kinyarwanda, and Swahili together because VC-concord can be with DPs and PPs. On the other hand Tswana and SiSwati are grouped together because VC-concord is only with DPs.

9 I base this comment on my own field research of Tswana. 


\subsubsection{Co-occurrence of concord and lexical XP: Yes/No}

This parameter distinguishes languages in which the VC-concord cannot cooccur with its co-referent XP like Tshiluba (Cocchia (2000)) one hand and languages like SiSwati, Chichewa and KiSwahili on the other, in which the VCconcord can co-occur with the co-referent XP.

In summary, this section has outlined the typological macro and micro parameters that I propose account for a significant portion of the licensing properties of complements and adjuncts in Bantu languages. Admittedly, the parameters are still sketchy at best and have only succeeded in suggesting a different way of thinking and of addressing the licensing of complements and adjuncts in Bantu. More empirical research and analysis is still to follow. As noted above, it is an empirical question why languages tend to use only two VCslots when in principle they have more options like Kinyarwanda. Further, it is also an empirical question whether the typological parameters discussed here can be reduced to cognitive parameters like Baker's (1996) Polysynthesis Parameter.

\section{Conclusion}

The study has presented a broad analysis of the complement and adjunct structure of Bantu languages. It proposes that there are inherent complements and derived complements on one hand and free adjuncts and derived adjuncts on the other hand. Crucially, it argues that syntactic rules refer to these broad classes as well as to syntactic category type. Thus syntactic rules can further distinguish between DPs, PPs and clauses.

The study also proposed that there are typological macro parameters that account for variation among languages generally. In addition it proposed that there are micro parameters that distinguish languages that make the same macro parameter choices. It illustrated that Bantu languages differ in terms of three micro parameters. It is an open question whether these typological parameters of variation can be reduced to cognitive parameters.

\section{References}

Alsina, A. (1996). Passive types and the theory of object asymmetries. Natural Language and Linguistic Theory, 14(4):673-723.

Bresnan J. and S.A. Mchombo (1987). Topic, Pronoun and Agreement in Chichewa. Language 63, no.4: 741-782.

Bresnan, J. and L. Moshi (1990). Object Asymmetries in Comparative Bantu Syntax. Linguistic Inquiry 21: 147-185. 
Bukuru, D. (1998). Object Marking in KiRundi and KiSwahili. Master's thesis. Dar es Salaam.

Baker, M. (1988). Theta Theory and the Syntax of Applicatives in Chichewa. Natural Language and Linguistic Theory 6: 353-380.

Baker, M. (1992). Thematic Conditions on Syntactic Structures: Evidence from Locative Applicatives. In Thematic Structures: Its Roles and in Grammar, ed. I. M. Rocca. Berlin and New York: Foris, 23-46.

Baker, M. (1996). The Polynthesis Parameter. Oxford: Oxford University Press.

Cocchi, G. (2000). Free Clitics and bound Affixes. In Clitics in Phonology, Morphology, and Syntax, ed. Gerlach et al. Amsterdam: John Benjamins, 85-119.

De Guzman, V. P. (1987). Indirect Objects in SiSwati. Studies in African Linguistics 18, 309325.

Gerdts, G. and L. Whaley (1991). Locatives vs Instrumentals in Kinyarwanda. In Proceedings of the Seventeenth Annual Meeting of the Berkeley Linguistics Society: Special Session on African Language Structures. Berkeley: University of California, 87-97.

Harford, C. (1991). Object Asymmetries in Kitharaka. In Proceedings of the Seventeenth Annual Meeting of the Berkeley Linguistics Society: Special Session on African Language Structures, Berkeley: University of California.

Marten, L. (2000). At the Syntax-Pragmatics Interface: Verbal Underspecification and Concept Formation in Dynamic Syntax. Oxford: Oxford University Press.

Mchombo, Sam (2004). The Syntax of Chichewa. Cambridge: Cambridge University Press.

Ngonyani, D. (1996). The Morphosyntax of Applicatives. Doctoral dissertation, UCLA.

Rugemalira, J. M. (1991) What is a symmetric Language? Multiple Object Constructions in Bantu. In Proceedings of the Seventeenth Annual Meeting of the Berkeley Linguistics Society: Special Session on African Language Structures. Berkeley: University of California, 200-209.

Schadeberg, T. C. (1995). Object diagnostics in Bantu. In E. N. Emenajo and O. Ndimele (eds.) Issues in African Languages and Linguistics: Essays in Honour of Kay Williamson, Chapter 16, pp. 173-180. Aba: National Institute for Nigerian Languages.

Williams, E. (1980) Predication. Linguistic Inquiry 11, 203-238.

Woolford, Ellen. (1995) "Why Passive can Block Object Marking." In Theoretical Approaches to African Linguistics (Trends in African Linguistics 1) ed. Akinbiyi Akinlabi, 199-215. Trenton, New Jersey: Africa World Press.

Woolford, Ellen. (1996) "Symmetric and Asymmetric Passives". Natural Language and Linguistic Theory 11, 679-728.

nt26@soas.ac.uk 